\title{
A Review on Rice Straw Management Strategies
}

\author{
Lakhvir Singh $\dagger$ and Balraj Singh Brar \\ Yadavindra College of Engineering, Punjabi University Guru Kashi Campus, Talwandi Sabo, Punjab, India \\ $\dagger$ Corresponding author: Lakhvir Singh; er.lakhvir723@gmail.com
}

Nat. Env. \& Poll. Tech.

Website: www.neptjournal.com

Received: 02-11-2020

Revised: 15-02-2021

Accepted: 22-02-2021

Key Words:

Rice Straw

Burning

Pollutions

Treatments

Environment friendly

\begin{abstract}
Rice straw is one of the organic materials and natural residue of rice crop or paddy material and is the third-largest residue from agriculture after sugarcane bagasse and maize straw. Southeast Asian countries produce approximately $80 \%$ of rice production in the world. It leads to a large quantity of rice straw as a by-product every year. Surplus rice straw is a focal issue associated with storage of rice straw, removal of entire straw from the field, and very little time between the cultivation of the crop. Stubble burning is a quick, cheap, and efficient way to prepare the soil bed for wheat, the next crop. Rice straw has both nutrient and calorific values. Straw is the only organic material available in significant quantities to most rice farmers. About 40 percent of the nitrogen $(N), 30$ to 35 percent of the phosphorus (P), 80 to 85 percent of the potassium (K), and 40 to 50 percent of the sulfur (S) taken up by rice remains in vegetative plant parts at crop maturity. Straw is either removed from the field, burned in situ, piled or spread in the field, or incorporated in the soil. Open burning of the crop residue kills useful microflora of soil, leads to soil degradation, and contributes to harmful greenhouse gases such as $\mathrm{SO}_{2}$, $\mathrm{NO}_{2}, \mathrm{CH}_{4}, \mathrm{~N}_{2} \mathrm{O}$, carbon monoxide in the atmosphere including the hydrocarbon and particulate matter. Therefore, rice straw burning is a serious creator of environmental pollution. The study investigated environment-friendly options of rice straw such as bedding material for cattle, mushroom cultivation, nutrition in the soil, power generation, combustion material, pellet making, bio-gas, bio-ethanol, biochar, acoustic material, 3D objects, cardboard and composite board, packaging materials, production of bio-composite, cement bricks, and handmade paper. The key purpose of this paper is to provide

environmentally friendly alternatives to rice straw instead of open field burning.
\end{abstract}

\section{INTRODUCTION}

Rice crop or paddy is a type of grass (Gramineae) and belongs to the genus Oryza. The rice Oryza glaberrima and rice Oryza sativa were domesticated in Africa and Asia respectively. Many other places have been proposed for the origin of $O$. sativa such as northern Thailand and India. In southern China, Yangzi valley is one of the domesticated rice places (Dobermann \& Fairhurst 2002, Singh et al. 1995). The $O$. sativa is cultivated in a wide range of environments. It is cultivated from lowland paddy fields to high altitude terraces, equatorial tropics to sub-tropical mid-latitude, and from swamps to upland rice. The maximum yield of paddy is obtained in the dry season, because of less cloud cover. With lesser cloud cover, the photosynthetic active radiations (PAR) are more as compared to the wet season (Dobermann $\&$ Fairhurst 2002).

The primary harvesting season for rice is from June to October for different regions and climates (Zhiqiang et al. 2011). For most of the traditional varieties, the growing season is of about 260 days. But in the case of modern varieties, the growing season reduces to 90-110 days. For increasing crop production, the shortening of the growing season plays a very important role. The time for crop maturity is usually extended because of a deficiency in phosphorus and other nutrients. Modern varieties of rice were introduced in the year 1960. Most of the paddy rice farmers cultivate is nitrogen $(\mathrm{N})$ responsive and short straw varieties (Dobermann \& Fairhurst 2002).

Rice straw is one of the organic materials and natural residue of rice crop or paddy material, which is easily available to most farmers worldwide (Dobermann \& Fairhurst 2002). Globally, it is the third-largest residue from agriculture after sugarcane bagasse and maize straw (McLaughlin et al. 2016).

\section{Problems in Paddy Straw Management: Worldwide and in India}

Southern and Southern Eastern Asia is the main producer of rice. From this region, China, India, Indonesia, Bangladesh, and Vietnam are the main rice-producing countries. That is why this region is the main focus of the study problem related to rice straw and its management (Bakker et al. 2013). As rice is the $2^{\text {nd }}$ largest cereal crop after wheat, more than 580 million tonnes of rice straw, a biomass, is produced every year (Nasr et al. 2015, Reddy \& Yang 2006). In India, 43.95 million hectares of land are under paddy cultivation, which produced nearly 106.54 million tonnes of rice and 
160 million tonnes of straw in the last few years. Usually, the ratio of rice grain to straw produced is 1:1.5. In the year 2013-14, Punjab, a small northern state of India, alone produced approximately 11.27 million tonnes of rice (about $10.6 \%$ of India's total production) and 16.90 million tonnes of rice straw (Chandra et al. 2017, Yadav et al. 2015).

It is noted that, traditionally, a major part of wheat straw is used as animal feed, but rice straw is of very low-quality roughage and hence not preferred as feed for the animals (Bakker et al. 2013). Compared to wheat straw, a very little part of rice straw is used in brick kilns, animal production/ grooming, mushroom cultivation, making of cardboards, as a fuel for biomass power plants, and many applications in industrial processes (Chandra et al. 2017, Yadav et al. 2015).

\section{Losses to the Environment and Soil Fertility Due to Traditional Handling of Rice Straw}

Open-field burning of rice straw leads to air, water, and land pollution, which is an enormous problem for the environment. Moreover, it contributes to climate change and increased ozone levels. In India, farmers of Punjab and Haryana states follow mechanized agriculture because of a shortage of labor and they need to prepare their field quickly for the cultivation of the next crop (Verma 2014). Open-field burning of crop residue produces very harmful gases like $\mathrm{SO}_{2}, \mathrm{NO}_{2}, \mathrm{CH}_{4}, \mathrm{~N}_{2} \mathrm{O}$, and carbon monoxide in the atmosphere including hydrocarbon and particulate matter (Pushpa \& Sinha 2011). Punjab Agriculture University, Ludhiana (PAU) estimated that crop residue contains carbon of about 6 million tonnes which upon open field burning, produces 22 million tonnes of carbon dioxide within a time period of 15-20 days (Kumar et al. 2015). The Supreme Court of India took a serious note of pollution due to stubble burning in Northern Indian states such as Punjab, Haryana, Delhi, and Uttar Pradesh (Kaur 2017).

The several nutrients detached from rice straw, rice grain, and combined (straw and grain) are as given in Table 1: To manage the current situation of stubble burning, alternative (Scientific methods) uses of rice straw need to be found, which are economical to farmers rather than a burden. Presently, many farmers have been using the traditional method of burning crop stubble which is easy, inexpensive, and efficient The study recommends some approaches that (if used appropriately) will profoundly assist in arresting the issues of burning agricultural stubble in the country and beyond (Vagg 2015). The two mains processing technologies for the conversion of rice straw to energy are: biochemical/ biological and thermochemical. Thermochemical processing comprises liquefaction, pyrolysis/gasification, and combustion. Biochemical processing comprises fermentation and digestion (Dobermann \& Fairhurst 2002, Bakker et al. 2013).

The main objective of this paper is to review the various rice straw management strategies and respective hurdles.

\section{Flow Diagram of Rice Straw Management Alternatives}

The state of the art of rice straw management techniques has been broadly classified as per the flow chart given below:

The flow chart shows two main classifications of rice straw management: in-field options and off-field options which are described as follows. The in-field options for rice straw management are further classified as direct open-field burning of rice straw and incorporation of rice straw into paddy soil is another strategy to manage rice straw. The offfield options are further classified into three main categories: agriculture/ dairy, energy production, and manufacturing. In the agriculture/ dairy category, rice straw is used for bedding material, mushroom cultivation, and compost purpose. The energy production category is divided into power generation (thermal) and bio-chemical. The power generation (thermal) category is further classified as generation of power from rice straw, rice straw as combustion material, and pallet making from rice straw. Another category of energy production is the biochemical process. With the help of biochemical processes bioethanol, biogas and biochar can be prepared from rice straw. Other miscellaneous uses of rice straw for manufacturing are as follows: acoustic material, 3D objects, cardboard composite, cement bricks, and handmade paper.

\section{Recent Review of Paddy Straw Management Endeavors}

To recent reviews of different rice straw management techniques are further discussed, as shown in the flow chart:

\section{Recent Review of in-Field Options for Rice Straw Management}

There are two key in-field options for rice straw management: open burning of rice straw and preparation of compost from the rice straw. These are further discussed below in detail:

- Open burning of rice stubble in the field: The burning of rice straw has a very harmful effect on the environment because of the generation of a large quantity of

Table 1: Values of Nutrients Removed (Dobermann \& Fairhurst 2002).

\begin{tabular}{|llllll|}
\hline \multicolumn{7}{|c|}{ Removal of Nutrients in kg/tonne } \\
\hline & $\mathrm{P}_{2} \mathrm{O}_{5}$ & $\mathrm{~N}$ & $\mathrm{~K}_{2} \mathrm{O}$ & $\mathrm{Mg}$ & $\mathrm{Ca}$ \\
\hline By rice straw & 2.3 & 7.0 & 17.5 & 2.0 & 3.5 \\
By rice grain & 4.6 & 10.5 & 3.0 & 1.5 & 0.5 \\
Straw and grain & 6.9 & 17.5 & 20.5 & 3.5 & 4.0 \\
\hline
\end{tabular}




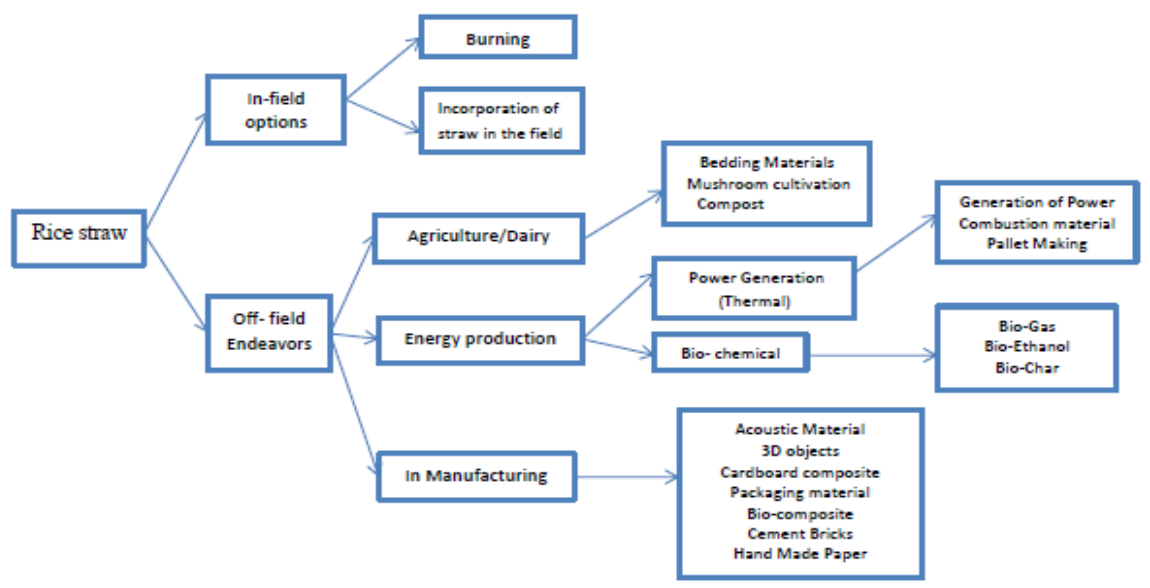

Diagram 1: Rice straw management alternatives.

$\mathrm{CO}_{2}$ gas that contributes to the greenhouse effect. It also affects the respiratory system of the local population of that area (Zayed \& Abdel-Motaal 2005). Paddy residue left by harvesters takes one-and-half months to decompose while farmers do not have sufficient time to sow their next crop, wheat. Stubble burning is a quick, cheap, and efficient way to prepare soil bed for wheat, the next crop (Chandra et al. 2017, Yadav et al. 2015). During the rice straw burning, lots of nutrients are lost as discussed in section 3 of this paper. So the farmers have to add various fertilizers and nutrients to compensate for the loss, which is an additional economic burden (Zhiqiang et al. 2011) (McLaughlin et al. 2016).

- Incorporation of rice straw in the field: The burning of crop residue leads to soil degradation (Yadav et al. 2015). Researchers are continuously working to develop rapid and simple composting methods for the conversion of waste rice straw into organically rich nutrients for the soil. In agriculture, the use of compost improves crop yield problems by $4-9 \%$ (Verma 2014).

To accelerate the breakdown process, some special fungus is added and it gives successful results just in 3 months. The addition of cow dung also provides the required environment for enzymes and microbes (Vagg 2015). A study showed that before incorporation, rice straw treated with Trichoderma harzianum, Pleurotus sajorcaju, and cow dung slurry enhanced the nutrients content and organic carbon of soil. It further increases straw yield and grains (Fig. 1) (Sanathimmappa et al. 2015).

\section{Recent Review of Off-Field Options for Rice Straw Management}

In off-field options, first, the rice straw is moved from the field and then converted into bundle form. The various off-field options are discussed as below:

\section{Rice Straw Uses in Agriculture and Dairy Purpose}

Use of rice residue as bedding material for cattle: The Punjab Agricultural University, Ludhiana advised the farmers to use rice straw as bedding material in winters for cattle (Fig. 2). Rice straw provides a dry, clean, comfortable, non-slippery, and hygienic environment which prevents the chances of lameness and injury. Healthy legs ensure better milk production and reproductive efficiency of animals (Kumar et al. 2015, Kargbo et al. 2010, Singh et al. 1995).

Paddy straw for mushroom cultivation: In 2017-18, India cultivated rice in an approximate area of 45.10 Mha and produced 111.01 MMT with a productivity rate of 3.52 MT.ha ${ }^{-1}$. Mushrooms were first cultivated in India in Coimbatore by Thomas et al. (1943). As per the FAO (Food and Agriculture Organization) statistics, in 2016, India produced 29992 tonnes of mushrooms and ranked $5^{\text {th }}$ in the world in mushroom production. Cultivation of mushrooms requires rice straw with some special moisture, length, and temperature (Yoshiro \& Duoug 2015, Kaushik et al. 2018).

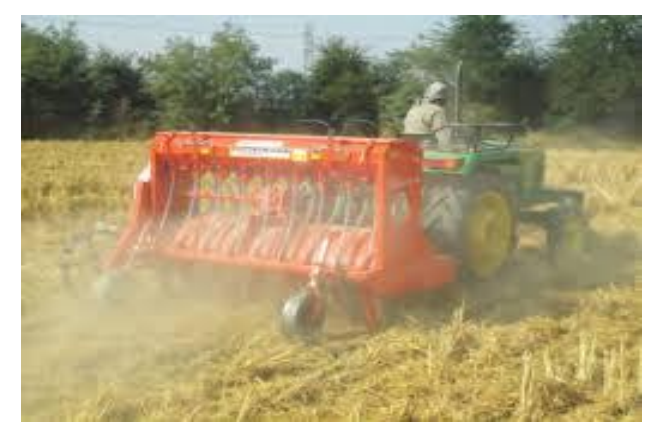

Fig. 1: Incorporation of rice straw in the field. 
The factors required for the proper growth of mushrooms are relative humidity of about $75-85 \%$ and $35^{\circ} \mathrm{C}$ temperature (Thiribhuvanamala et al. 2012). The production cycle of paddy straw mushrooms is 15 days only (Fig.3) (Kaushik et al. 2018) (Tripathy 2010).

Rice straw as nutrients for the soil: Rice straw has both nutrient and calorific values (Yoshiro \& Duoug 2015). In composting process, the degradation of organic wastes by communities of microbial takes place (Tang et al. 2007). The composting process has many advantages like bulk and mass reduction, high $\mathrm{C} / \mathrm{N}$ ratio (carbon to nitrogen), and sanitation. The produced compost is stable and used in agricultural applications and also helps in the growth of plants (Abdelhamid et al. 2004). Because of the high $\mathrm{C} / \mathrm{N}$ ratio, rice straw resists microbial activity. So for better results, composting of rice straw is done with some other organic wastes. Composting process converts the unstable ammonia to stable organic material, can destroy the pathogens, and reduce waste, thus, meeting the requirements to be used as fertilizers. In the composting process, factors that affect the quality of compost are the $\mathrm{C} / \mathrm{N}$ ratio, moisture content, temperature, ph. value, degree of aeration, and structure (Physical) of the waste material (Rashad et al. 2010, Li et al. 2007).

\section{Rice Straw for Energy Production}

Power generation (thermal) from rice straw: Power can be generated by using rice straw as a fuel or raw material deliberated below one by one:

Rice straw for generation of power: Currently, bioenergy is the largest renewable energy source globally and accounts for more than $2 / 3 \mathrm{rd}$ of the renewable energy mix. In the overall energy scenario, bioenergy accounts for $13 \%-14 \%$ of the total energy consumption (Fig. 4). Crop residues, in particular, are one of the largest biomass resources globally and the best options for use to produce bioenergy (Yadav et al. 2015, Kargbo et al. 2010). In India, Punjab Biomass

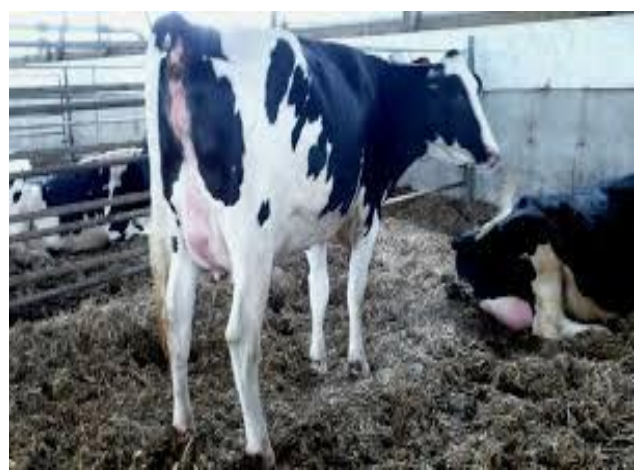

Fig. 2: Rice straw as bedding material for cattle.
Power Limited in village Ghanaur of Patiala Distt. (Punjab) was the first power plant working on rice straw for the production of power with a capacity of 12 MW Power (Vagg 2015). In Zimbabwe, $47 \%$ of the energy consumed is taken from biomass and a major part of this biomass is the residue of crops (Yadav et al. 2015). The thermal efficiency of rice straw is approximately $60-75 \%$ which may further depend on the technology used in its combustion. The two main obstacles for rice straw to be considered as a biomass fuel are logistics and consistency of product (Vagg 2015). Uniform combustion of straw takes place when baled form of straw is converted into shredded form (Verma 2014).

Rice straw as combustion material: Rice straw can also be used as a feedstuff, fuel, industrial raw material, and fertilizer. For the combustion of agriculture wastage, combustors are used as grate-fired and fluidized bed or suspension burners systems. Grate-firing systems have many benefits like low investment cost, handle rice straw contains $65 \%$ water by weight, and little dust particles in flue gases. For the combustion of both biomass and coal, fluidized beds combustors are used. Fluidized beds combustors have higher combustion intensity when compared to the grate-firing system, and $\mathrm{NO}_{2}$ emission is highly controlled in fluidized beds system (Zhiqiang et al. 2011). It was investigated that if the moisture content in a baled straw is more than $25 \%$, then fermentation of straw starts. Moreover, it is expensive to transfer straw with moisture from one place to another (Zhiqiang et al. 2011).

Lots of parameters should be considered while designing a large-scale rice straw combustion system. These parameters are volatile matter content, the mean value, the possibility of moisture, agglomeration characteristics, ash composition, ash content, and energy content of the fuel. Various by-products like bottom ash, fly ash, etc. produced have economic value, and these may be further used in the manufacturing of bricks, cement, embankments, and construction of roads (Verma 2014) (Fig. 5).

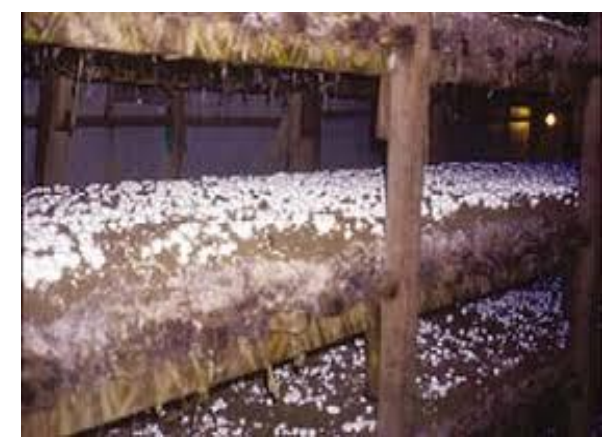

Fig. 3: Rice straw for mushroom cultivation. 
Rice stubble for pellets making: In pallet manufacturing, initially, the raw material (biomass) is crushed and then pressed for increasing density and forming. Then, solid pellets of biomass fuel are formed which are small in size. The pellet fuel has more efficiency, easy to store, and can solve the problem of coal and pollution. Pellet biomass fuel (Fig.6) has many advantages: high combustion efficiency, small volume, easy transportation, and storage. These advantages of pellet biomass fuel replace coal, wood, gas, oil, etc. as fuel. It is usually used in hot water boilers, life stoves, biomass power plants, and industrial furnaces (Verma 2014).

Energy Production from rice straw by biochemical methods: By applying different treatments to rice straw, different types of energy can be created. These are discussed as follows:

Biogas from rice straw: For the production of biogas from rice straw, underground containers usually have $2.5 \mathrm{~m}$ width, $4 \mathrm{~m}$ height, with a dome shape on top, and constructed with cement and bricks (Fig. 7). At the top of the container, a way for the gas outlet is provided and at the bottom, there is a way for the water inlet. A half-meter thick layer of rice straw and a layer of cow dung are placed alternately on the straw layer. These steps are repeated continuously till the complete filling of the plant. Later the plant is filled with water, and the fermentation process begins and production of biogas starts

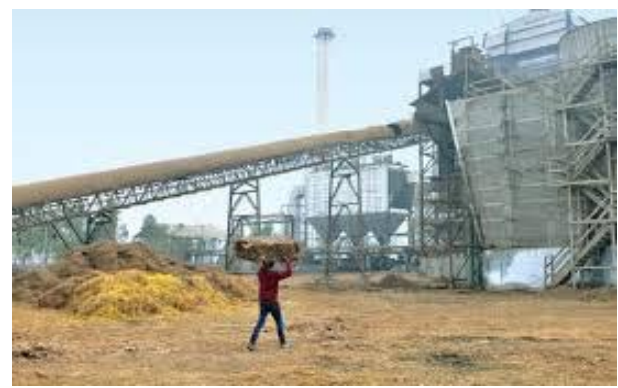

Fig. 4: Power generation from rice stubble.

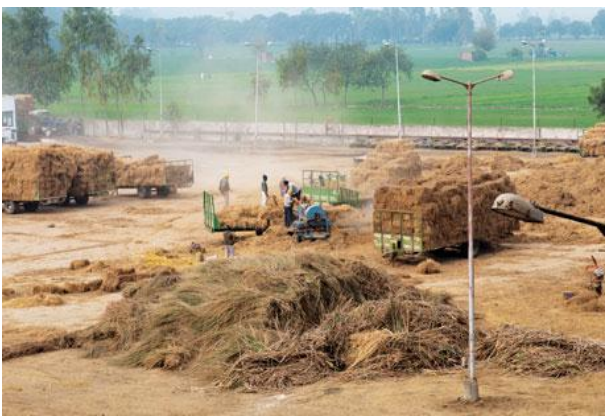

Fig. 5: Rice straw as combustion material. after one week. From one tonne of straw, 5-6 cubic meters of biogas is produced for 4 months continuously. By-products from the plant are utilized as fertilizers (Vagg 2015).

\section{Rice straw for Bioenergy (Biogas) with a New Approach}

Dr. B.S. Chadha investigated that before using rice straw for the production of biogas, several extraordinary value products are extracted from it. Generally, these products are hemicellulose, cellulose, and lignin (Dhap \& Singh 2017, Nasr et al. 2015). Rice straw has hemicellulose $19-27 \%$, cellulose $32-47 \%$, ashes $18.8 \%$ and lignin $5-25 \%$ (Yoswathana \& Phuriphipat 2010). Cellulose is extracted in solid form, some of it as a sugar-rich hydrolysate, and most of the hemicellulose is extracted as hydrolysates. With help of hydrolysis, hemicellulose and cellulose release xylooligosaccharides which are sugar polymer and ethanol is its last product. Highly valuable lignin is extracted during thermochemical pretreatment of rice straw by nano-filtration technique (membrane). Extracted lignin is non-toxic in nature that makes it a raw material for tire, cement application, computer's silica chip, antioxidants, manufacturing of carbon fiber, grease, and foams of polymers (Vagg 2015).

Rice straw for bioethanol production: As population increases, the demand for petroleum, diesel, coal, etc.

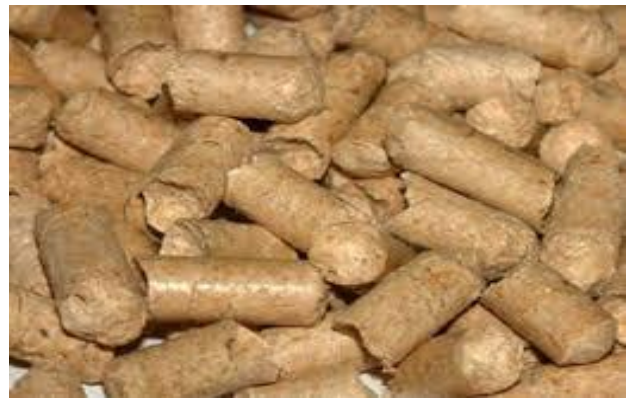

Fig. 6: Rice straw for pellets production.

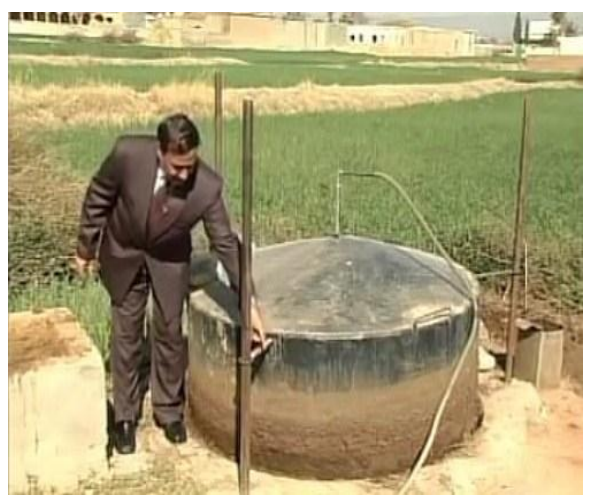

Fig. 7: Bio-gas from rice straw. 
increases, and the supply of these non-renewable sources also increases but its availability decreases gradually. The creation of ethanol from the cellulosic material of rice straw solves various problems (environment, energy, and economic) faced globally. Nowadays for transportation purposes, bioethanol fuel is recommended. Combustion of bioethanol produces volatile organic compounds, $\mathrm{CO}, \mathrm{NO}$ in very low concentrations and does not release $\mathrm{CO}_{2}$ in the atmosphere (Dhap \& Singh 2017). In recent years, from a list of renewable resources, ethanol is an alternate fuel to different fossil fuels. 205 billion liters of bioethanol is produced from rice straw each year, i.e. $5 \%$ of its total consumption of fuel (Yoswathana \& Phuriphipat 2010) (Fig 8.).

For the extraction of bioethanol from the rice straw as raw material, there are three main steps are: In the first step, during the pretreatment, lignin is removed and then converted into monomeric sugar (hexose and pentose).

In the second step, hydrolysis takes place for proper cleaning of the polymer of hemicellulose and cellulose by using enzymes for the production of glucose monomers. In the third step, the fermentation process takes place for the production of bioethanol from glucose. There are different pretreatment processes for the production of bioethanol such as chemical (sodium chloride and sodium hydroxide, Alkaline hydrogen peroxide), physical (Milling, Milling and autoclaving, Milling and gamma irradiation, subcritical water, Ultrasonic), or biological. May be a combination of chemical and physical (Phosphoric acid, Aqueous-ammonia soaking, Sulfuric acid, Sodium hydroxide, wet air oxidation lime) treatments can be applied for the production of bioethanol (Dhap \& Singh 2017).

Rice straw for biochar: Biochar is a type of charcoal that is derived biologically with thermochemical pyrolysis of rice straw (biomass). Pyrolysis is a thermochemical decom-

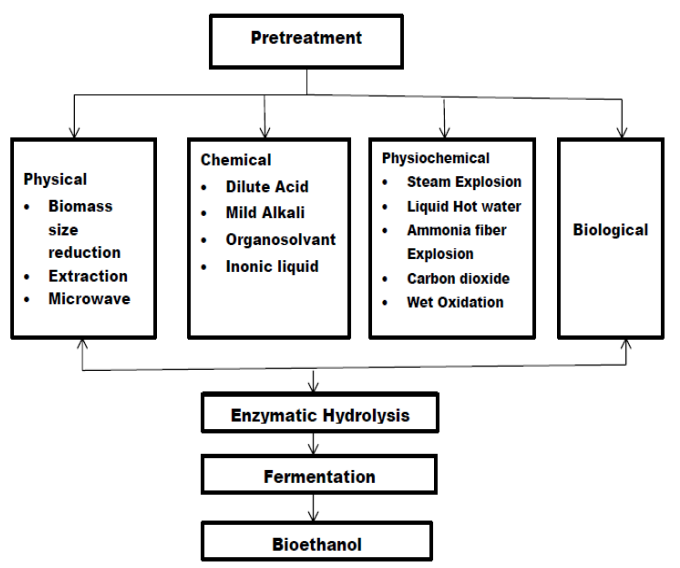

Fig. 8: Production of bio-ethanol from rice straw (Tayab et al. 2018). position of organic materials at an elevated temperature in absence of oxygen. In the pyrolysis process, larger molecules break down into small molecules. Although biochar can never add nutrients itself in soil, it increases the $\mathrm{pH}$ value in an area that is acidic in nature. So, with the help of biochar (Fig. 9), there may be a reduction in greenhouse gases, increase in crop yield, and the soil is provided with more fertility (Yoshiro \& Duoug 2015).

\section{Manufacturing From Rice Straw}

In different types of manufacturing, trend changes to using biodegradable raw materials in various kinds of production. Some of these are discussed below:

Rice straw for manufacturing of acoustic material: The construction of acoustic material is divided into 2 different stages. In the first stage, the rice straw must be dried for a week to remove the moisture present in the straw. After that, it is heated usually at $80^{\circ} \mathrm{C}$ for $5 \mathrm{~min}$ in the oven for complete evaporation of moisture. The raw material was then cut into 5 to $10 \mathrm{~mm}$. To have a compact structure, the fibers were then mixed with a binding agent, namely, polyurethane. The composition of the fibers and the binder was roughly $90 \%$ and $10 \%$ by weight, respectively. In the second stage of fabrication, the mixture is hot-pressed into a mold of a round shape $33 \mathrm{~mm}$ in diameter so that it must fit into an impedance tube during the sound absorber test (Fig. 10).

Putra et al. (2013) fabricated different absorber samples with different thicknesses of $10 \mathrm{~mm}$ and $20 \mathrm{~mm}$. For each thickness, the weight of the fiber is given for 2 grams and 4 grams which yields different fiber densities. The bulk density for each sample can be simply calculated by the ratio of the total mass of the sample and its volume. The sample with more density showed more fibers in the same thickness i.e. pores size reduced that leads to more sound energy loss. The experimental results show that this natural fiber can be utilized as a potential alternative acoustic material.

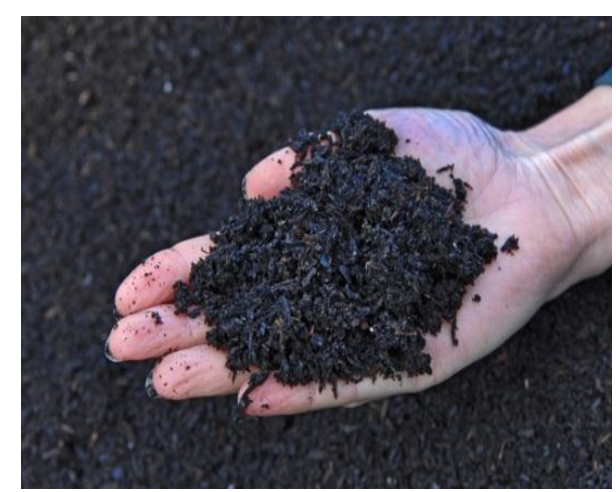

Fig. 9: Bio-Char from the rice straw. 
With a thickness of $20 \mathrm{~mm}$ and 3 grams of fiber weight, the absorption coefficient is more than 0.5 above $1 \mathrm{kHz}$ and can reach 0.8 on average above $1.5 \mathrm{kHz}$, comparable with the performance of synthetic glass wool with the same thickness. By introducing a single layer of polyester fabric to the sample's facing, further improvement of sound absorption can be obtained (Putra et al. 2013).

It is studied that from a mixture of rice straw and wood particles, sound-absorbing composites can be manufactured. Wood particles used up to $20 \%$ by wt. as a raw material for sound absorbing composites without a decrease in bonding strength (Yang et al. 2003).

Mixing with plastics for $3 D$ objects: Recently a company in China invented an eco-friendly material- straw-based plastic - made from rice and wheat stalks and can be used in 3D printing. It is prepared from the dried straw of crops like rice straw, wheat straw, corn stalk, etc., mixed with plastic and plastic additives. The process starts with shredding the straw to $1.5 \sim 2 \mathrm{~mm}$ pieces. Then they mix the straw dust with polypropylene, adding a silane coupling agent and ethylene bis(stearamide) as additives. The mixture is then extruded into granules using a twin-screw extruder. After the transformation, the granules have even particle size and are more stable for further processing. The plastic granules can be heated up to $160^{\sim} 180^{\circ} \mathrm{C}$ for injection molding. Using special filament extruders, the company has turned these plastic granules into filament for $3 \mathrm{D}$ printers. The $3 \mathrm{D}$ printed object created using the straw-based filament has the color of natural wood and the texture of plant fiber on the surface. It has also a nice surface finish and high strength (Verma 2014).

Rice straw for cardboard and composite board: Composite boards manufactured (Fig. 11) from rice straw and waste tire particles have better flexural properties than insulation boards, plywood, wood particle boards, and fibreboards (Yang et al. 2004). So, rice straw is an alternate source of fiber in the manufacturing of cardboard, and hence, it reduces the cutting down of trees for the purpose of making cardboard.

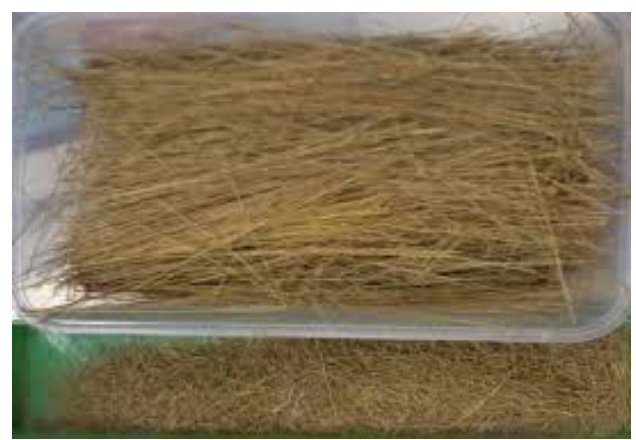

Fig. 10: Acoustic material from rice straw.
In the production of paper and cardboard, more than $65 \%$ of rice straw is transformed into useful pulp (Verma 2014).

Manufacturing of packaging materials: The good resilience and compact resistance property of rice straw make it useful for the manufacturing of virtuous packaging material replacing costly petroleum-based products (Verma 2014, Singh et al. 1995).

For the production of biocomposite: Agro-based biocomposite (Fig. 12) is prepared by using the eco-polyalcohol polymer-based adhesive system from rice straw. In the manufacturing of lignocellulosic composite, formaldehyde-based adhesives are used worldwide because of their noble adhesive properties. Epidemiology studies have inferred a possible association between formaldehyde exposure and increase risk of cancer. In the manufacturing of composite rice straw, three types of sizes are used. Their particle sizes are $<4.75 \mathrm{~mm}<2.63 \mathrm{~mm}<\mathrm{RS}<4.75 \mathrm{~mm}, 1 \mathrm{~mm}<\mathrm{RS}<2.63 \mathrm{~mm}$, and $500 \mu<\mathrm{RS}<1 \mathrm{~mm}$. For blending of these particles, polyalcohol polymer-based adhesives are used. The mass percentage of adhesive to dry rice straw of $12-16 \%$ was used. Hot pressing of material at $130^{\circ} \mathrm{C}$ temperature and pressure at 140 bars for 7 min takes place in the manufacturing of board. The final dimension of rice straw composite was approximately $8 \mathrm{~mm}$ thickness and density ranged from $905-1001 \mathrm{~kg} \cdot \mathrm{m}^{-3}$. The performance of the prepared board with environmental impact, commercial UF, and binding treated RS was compared. The TS and water absorption capability of the composite were measured after $24 \mathrm{~h}$ immersion in distilled water at $20^{\circ} \mathrm{C}$. Thermogravimetric analysis of rice straw composite takes place with the help of Perkin Elmer, performed at $50 \mathrm{cc} \cdot \mathrm{min}^{-1}$ nitrogen flow rate and $10^{\circ} \mathrm{C} \cdot \mathrm{min}^{-1}$ heating rate under non-isothermal conditions. The results showed that incorporating PVA up to $17 \%$ to starch increased the bonding strength. Moreover, this trend can reverse with more PVA quantity (20-67\%). Also, a pressing temperature of $130^{\circ} \mathrm{C}$, pressing time of $7 \mathrm{~min}$, and adhesive synthesized from $17 \%$ PVA and $83 \%$ corn starch contribute to higher bond strength. Due to

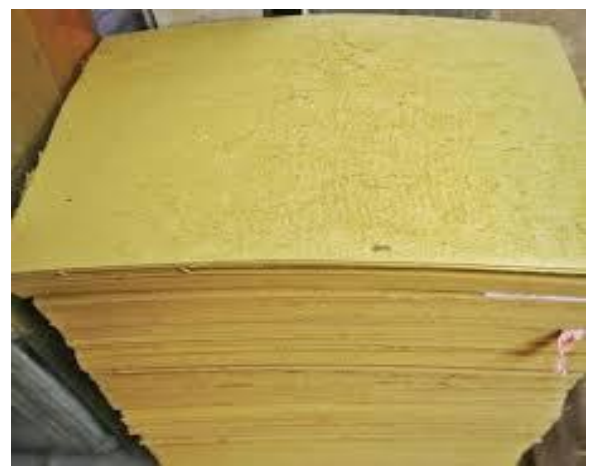

Fig. 11: Cardboard of rice straw. 
the applied pressure, compression of fibers takes place which leads to reduction of voids and porosity in the manufactured board that gives higher water-resistant property and density (Basta et al. 2013).

Rice straw-cement bricks: Rice straw is also being used for the production of lightweight cement bricks (Fig. 13) that are used as fillers in the construction of buildings (skeleton types). The burned product of biomass power plant left behind contains high silica contents and is used in the manufacturing of bricks (Vagg 2015). Allam \& Garas (2010) investigated that a sun-baked mud brick without straw had strength less than $6 \mathrm{kp} . \mathrm{cm}^{-2}$, however, with the addition of straw, these bricks become three times stronger, about $20 \mathrm{kp} . \mathrm{cm}^{-2}$. Moreover, the straw used in the production of bricks also provides thermal insulation to it. Coarse and fine aggregates were batched by volume using wooden boxes with the desired volume. Cement was added by weight using only whole bags of $50 \mathrm{~kg}$ to ensure uniform proportions of mix. The chopped rice straw was added to the mixture according to the previously mentioned quantities. The dry mixes were batched outdoors in a rotating power-driven resolving mixer of 100 liters capacity before adding water. Then the bricks were molded and vibrated and then de-molded immediately

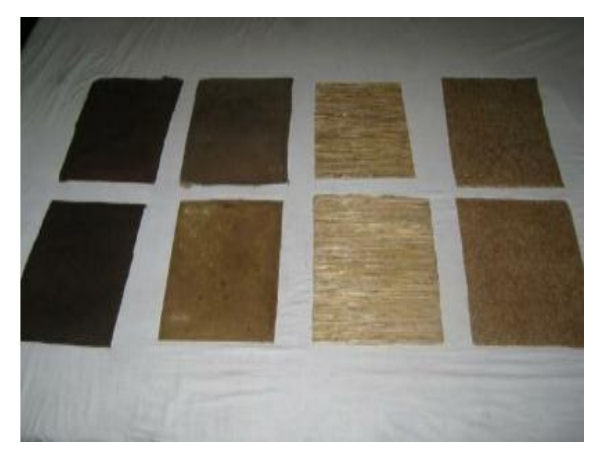

Fig. 12: Bio-composite of rice straw.

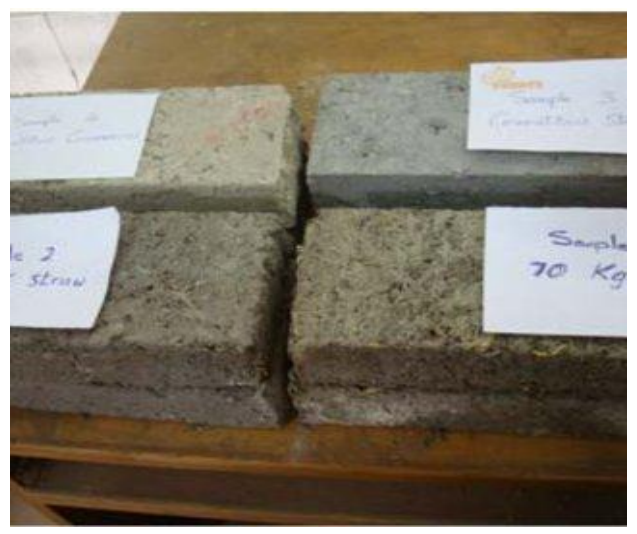

Fig. 13: Rice straw cement bricks. after compaction. These samples were placed for curing purposes and water sprayed twice a day up to 7 days for the proper gaining of strength in bricks. It was investigated that bricks prepared by this method maintain compression stress up to $115 \mathrm{~kg} . \mathrm{cm}^{-2}$ moreover; the production cost reduced by $25 \%$ as compared to pure cement bricks (Allam \& Garas 2010).

Rice straw for handmade paper: Agriculture residue has high fibrous lignocellulose and a large quantity of hollocellulose content which makes it a raw material for the paper industry (Kadam et al. 2000). In this technology, acetic acid pulping in presence of $\mathrm{H}_{2} \mathrm{SO}_{4}$ as a catalyst is used under different conditions. The main reaction variables are the concentration of Acetic acid (\%), catalyst ( $\mathrm{HCl}$ or $\mathrm{H} 2 \mathrm{SO} 4 \%$ ) concentration, the ratio of liquid to straw, reaction time, and temperature. Good quality of pulp is produced, when acetic acid concentration is $85 \%$, liquid to straw ratio is taken as 10 , the reaction temperature is $90^{\circ} \mathrm{C}, \mathrm{H}_{2} \mathrm{SO}_{4}$ concentration is $1 \%$, and reaction time taken in pulp production is 180 min. The produced pulp is used to manufacture handmade paper (Fig. 14) and carry bags because of better mechanical properties (Pushpa \& Sinha 2011).

\section{CONCLUSION}

Proper utilization of rice straw is not only the responsibility of farmers; government should have to make proper laws and regulations to check stubble burning. There must be public awareness regarding rice straw management and compulsory training must be given to farmers related to rice straw management. To curb the menace of stubble burning during the post-harvesting season in the state, the Punjab Pollution Control Board (PPCB) has urged all owners to ensure the attachment of Super Straw Management System (SMS) with their self-propelled combine harvesters. The Super Straw Management System (SMS) cuts the residue rice straw into small pieces and spread it in the fields. Uses of rice straw also provide some financial support to farmers. Rice straw can be used for different purposes as a fuel that may reduce greenhouse and other harmful gases. In this way, the environment can be protected from the future critical situation of pollution. The technology should be such that rice straw can be transported from the field to industry with minimum effort otherwise all efforts are a failure. Private players have to use their new and old technologies for better practice of stubble by setting up units locally. It has been already discussed that rice straw can replace non-renewable energy fuel. These steps save the environment for our future generation. Small power thermal plants may also replace their fuel and operate on stubble in the future. The government should implement subsidies plans to promote the consumption of these 


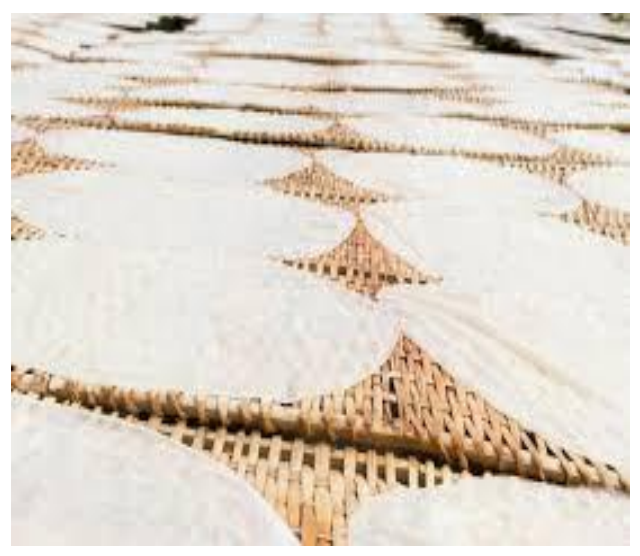

Fig. 14: Rice straw hand made paper.

biofuels. In India and other countries, local authorities can be more responsible in setting specific prohibitions. Some NGOs (Non-Government Organization) have also started microfinance in Bangladesh and Indonesia for small-scale renewable energy projects.

\section{REFERENCES}

Abdelhamid, M. T., Horiuchi, T. and Oba, S. 2004. Composting of rice straw with oilseed rape cake and poultry manure and its effects on faba bean growth and soil properties. Elsevier, 93: 183-189.

Allam, M. and Garas, G. 2010. Recycled chopped rice straw-cement bricks: An analytical and economical study. Trans. Ecol. Environ., 140: 79-86.

Bakker, R., Elbersen, W., Poppens, R. and Lesschen, J. P. 2013. Rice Straw and Wheat Straw Potential Feedstocks for the Biobased Economy. Wageningen UR, Food \& Biobased Research, NL Agency Ministry of Economic Affairs, The Netherlands,

Basta, A., El-Saied, H. and Lotfy, V. 2013. Performance of rice straw-based composites using environmently friendly polyalcoholic polymer-based adhesive system. Pigment. Resin Technol., 42(1): 24-31.

Chandra, R., Trivedi, A., Jha, B., Verma, A. R. and Vijay, V. K. 2017. Energy Generation from Paddy Straw. Akshay Urja, Delhi.

Dhap, N. and Singh, H. 2017. Pretreatment of rice straw for bio-ethanol production: A review. J. Chem. Pharm. Res., 9(4): 216-220.

Dobermann, A. and Fairhurst, T. 2002. Rice straw management. Better Crops Int., 16: 1-11.

Sanathimmappa, H.G., Gurumurthy, B.R., Jayadeva, H.M., Rajanna, D. and Shivanna, M.B. 2015. Effective Recycling of Paddy Straw through Microbial Degradation for Enhancing Grain and straw Yield in Rice. IOSR Journal of Agriculture and Veterinary Science, 8(1), 70-73.

Kadam, K.L., Forrest, L.H. and Jacobson, W.A. 2000. Rice straw as a lignocellulosic resource: Collection, processing, transportation, and environmental aspects. Elsevier Sci., 18: 369-389.

Kargbo, F.R., Xing, J. and Zhang, Y. 2010. Property analysis and pretreatment of rice straw for energy use in grain drying: A review. Agric. Biol. J. North Amer., 1(3): 195-200.

Kaur, A. 2017. Crop residue in Punjab agriculture: Status and constraints. J. Krishi Vigyan, 5(2): 22-26.

Kaushik, S., Ipsita, D. and Kumar, S. 2018. Paddy straw mushroom: A natural scavenger who helps in malnutrition and environmental protection. Int. J. Microbiol. Res., 10(5): 1183-1185.

Kumar, P., Kumar, S. and Joshi, L. 2015. Socioeconomic and Environmental Implications of Agricultural Residue Burning. Springer, London.
Li, X., Zhang, R. and Pang, Y. 2007. Characteristics of dairy manure composting with rice straw. Bioresour. Tech., 99: 359-367.

McLaughlin, O., Mawhood, B., Jamieson, C, and Slade, R. 2016. Rice Straw for Bioenergy: The Effectiveness of Policymaking and Implementation in Asia. 24th European Biomass Conference and Exhibition at Amsterdam, The Netherlands, 6-9 June 2019, pp. 1-16

Nasr, A.M., Badawi, M.H., Demerdash, M.A. and Barakat, O.S. 2015. Bioconversion of Rice straw into Ethanol: Fungi and yeasts are the Bachbone Microbiota of the process. Int. J. Curr. Microbiol. Appl. Sci., 4(12): 382-401.

Pushpa, J. and Sinha, A. 2011. Application of rice straw as raw material for the production of handmade paper. IPPTA, 23(2): 145-148.

Putra, A., Abdullah, Y., Efendy, H., Mohamad, W. and Salleh, N. 2013. Biomass from paddy waste fibers as sustainable acoustic material. Adv. Acoust. Vib., 2013: 1-7.

Rashad, F.M., Saleh, W.D. and Moselhy, M.A. 2010. Bioconversion of rice straw and certain agro-industrial wastes to amendments for organic farming systems: 1 . Composting, quality, stability, and maturity indices. Elsevier, 101: 5952-5960.

Reddy, N. and Yang, Y. 2006. Properties of high-quality long natural cellulose fibers from rice straw. J. Agric. Food Chem., 54(21): 8077-8081.

Singh, R.B., Saha, R.C., Singh, M., Chandra, D., Shukla, S.G., Walli, M. and T.K. 1995. Rice Straw- its Production and Utilization in India. ICAR, New Delhi.

Tang, J.C., Shibata, A., Zhou, Q. and Katayama, A. 2007. Effect of temperature on reaction rate and microbial community in composting of cattle manure with rice straw. J, Biosci. Bioeng., 104(4): 321-328.

Tayyab, M., Noman, A., Islam, W., Waheed, S., Arafat, Y. and Ali, F. 2018. Bioethanol production from lignocellulosic biomass by environment-friendly pretreatment methods: A review. Appl. Ecol. Environ. Res., 6(5): 225-249.

Thiribhuvanamala, G., Krishnamoorthy, S., Monoranjitham, K., Praksasm, V. and Krishnan, S. 2012. Improved techniques to enhance the yield of paddy straw mushroom (Volvariella volvacea) for commercial cultivation. Afr. J. Biotechnol., 11(64): 12740.

Tripathy, A. 2010. Yield evaluation of paddy straw mushrooms (Volvariella Spp.) on various lignocellulosic wastes. Int. J. Appl. Agric. Sci., 5(3): 317-326.

Vagg, A. 2015. Rice Straw Utilisation. Nuffield Australia Farming Scholars, Australia.

Verma, D. 2014. Technologies for stubble use. J. Agric. Life Sci., 1(2): 106-110.

Yadav, M., Prawasi, R., Satyawan, R.P., Kumari, K. and Karamdeep, R. 2015. Assessment of Rice Straw Burning and its power generation potential in major rice-growing districts of Haryana, India. Int. J. Sci. Eng. Technol. Res., 4(5): 1287-1293.

Yang, H., Kim, D. and Kim, H. 2003. Rice straw-wood particle composites for sound absorbing wooden construction materials. Biosour. Technol., 86(2): 17-121.

Yang, H., Kim, D., Lee, Y., Kim, H., Jeon, J. and Kang, C. 2004. Possibility of using waste tire composite reinforced with rice straw as construction material. Biosour. Technol., 95(1): 61-65.

Yoshiro, H. and Duoug, P.T. 2015. Current Situation and possibilities of Rice Straw Management in Vietnam. University of Tsukuba.

Yoswathana, N. and Phuriphipat, P. 2010. Bioethanol Production from Rice Straw. Energy Res. J., 1(1): 26-31.

Zayed, G. and Abdel-Motaal, H. 2005. Bio-active composts from rice straw enriched with rock phosphate and their effect on the phosphorous nutrition and microbial community in the rhizosphere of cowpea. Elsevier, 96, 929-935.

Zhiqiang, L., Xu, A. and Zhao, T. 2011. Energy from the combustion of rice straw: Status and challenges to China. Energy Power Eng., 3: 325-331. 